\title{
Dynamics of Intramolecular Spin Exchange Interaction of a Nitronyl Nitroxide Diradical in Solution and on Surfaces.
}

\author{
V. Lloveras, E. Badetti, J. Veciana and J. Vidal-Gancedo
}

\begin{abstract}
In this paper we study the dynamics of thermally modulated intramolecular spin exchange interaction of a novel diradical nitronyl nitroxide-substituted disulfide in solution and when it is grafted on gold surface. The structure of this diradical was designed to have flexible chains to lead intramolecular collisions and hence spin exchange interaction, and with an appropriate binding group to be grafted on gold surface to study its behavior on surface. In solution, this diradical shows a strong spin exchange interaction between both radicals which is modulated by temperature, but also gold nanoparticles (Au NPs) functionalized with this diradical permit to investigate such a phenomenon in surface-grafted radicals. The spin-labelled AuNPs synthesis were optimized to obtain high coverage of spin labels to lead high spin exchange interaction. The obtained AuNPs were studied by Electron Paramagnetic Resonance (EPR), UV-Vis, and IR spectroscopies, HR-TEM microscopy, Cyclic Voltammetry (CV), Energy Dispersive X-ray analysis (EDX) and Thermogravimetric Analysis (TGA). This inorganic-organic hybrid material also showed dipolar interactions between its radicals which were confirmed by the appearance in EPR spectra of an $\left|\Delta m_{s}\right|=2$ transition at half-field. This signal gives direct evidence of the presence of a high-spin state and permitted to study the nature of the magnetic coupling between the spins which was found to be antiferromagnetic.
\end{abstract}

Self-Assembled Monolayers (SAMs) of these radicals on Au (111) substrate were also prepared and studied by contact angle, X-Ray Photoelectron Spectroscopy (XPS), time-of-flight secondary ion mass spectroscopy (ToF-SIMS), cyclic voltammetry (CV) and EPR. The magnetic as well as the electrochemical properties of the hybrid surfaces were studied and compared with the properties of this diradical in solution. Analogies between the properties of AuNPs with high coverage of radicals and those of SAM were observed.

\section{Introduction}

The interactions between unpaired electrons in organic diradicals are essential in many areas such as molecular charge transfer, ${ }^{1}$ organic magnetism, ${ }^{2,3,4}$ and spin labeling in biology. ${ }^{5}$ When unpaired electrons are in close proximity, the dominant interaction is likely to be spin-spin exchange coupling, which is the basis for bulk magnetic phenomena. In flexible diradicals spin exchange coupling is mainly mediated by intramolecular collisions. However, rigid di- or polyradical scaffolds, which are too constrained to allow intramolecular collisions, can show spin exchange coupling by through-bond and/or through-space mechanisms. ${ }^{6}$

There are some studies on intramolecular spin exchange in di- and polynitroxides, ${ }^{7,8}$ as well as a few with nitronyl nitroxide diradicals. ${ }^{9}$ Most of them are focused on their magnetic properties, and, to the best of our knowledge, there is only one work about intramolecular spin exchange dynamics with nitronyl nitroxides in solution. ${ }^{10}$ However, there is no detailed a quantitative study neither of the dynamics nor of the thermodynamics of such a process.

Here, we provide quantitative information of the dynamics and thermodynamics of a thermally activated intramolecular spin exchange interaction process mediated by intramolecular collisions of a novel nitronyl nitroxide diradical in solution and when it is grafted on surfaces of gold like in gold nanoparticles (AuNPs) and Au(111) flat surfaces. Dynamics of intramolecular spin exchange interaction is of significant importance for developing functional hybrid surfaces based on gold nanoparticles since they have high stability, are relatively easy to prepare and functionalize ${ }^{11}$ and hence are promising building blocks for designing new materials. ${ }^{12}$ In addition, the unique and size-dependent optical, electronic, and catalytic properties of nanoparticles make them interesting solid supports to investigate organic free radicals immobilized on their surfaces; and they have many potential applications in nanomedicine, ${ }^{12,13}$ as biosensors, ${ }^{13}$ in cancer therapy, ${ }^{14}$ catalysis, ${ }^{15,16}$ optoelectronics, ${ }^{17}$ spintronics, ${ }^{18}$ etc.

Gold nanoparticles functionalized with organic radicals were first reported in 2002, using a stable diradical TEMPO-substituted disulfide ${ }^{19}$ and there are only a few reports on spin-labeled gold nanoparticles in the literature, ${ }^{15,20}$ most of them based on TEMPO radicals. Recently, we have presented a method that permits to obtain in a one-pot reaction monodispersed Au nanoparticles with controlled size and high coverage of TEMPO radicals, showing interesting magnetic properties. ${ }^{36}$ However, a study of the dynamics of spin exchange interaction between surface-anchored radicals with temperature is, to the best of our knowledge, lacking. Chechik et al. ${ }^{19}$ monitored by EPR the dynamics of the anchoring of different nitroxide spin probes with disulfide groups on AuNP surfaces by ligand exchange reaction. Maggini et al. ${ }^{21}$ suggested a rapid EPR method to assess the dynamics, in terms of rigid/mobile fraction of an alkyl nitroxide grafted onto a porous silicon substrate, as a function of temperature. Gatteschi et al. ${ }^{22}$ made an EPR temperature study of a SAM of a nitronyl nitroxide derivative deposited on gold which did not show spin exchange interaction but only the typical broadening of the lines at lower temperature due to the freezing of the radical motion. In addition to this, it is worth mentioning that there is reported only one work about AuNPs 
coated with nitronyl nitroxides. ${ }^{23}$ On the other hand, only very few studies of nitronyl nitroxide radicals on Au(111) or other surfaces are reported. $22,24,25,26$

Here, we report the synthesis, characterization, and an intramolecular spin exchange dynamics study of a novel nitronyl nitroxide based diradical in solution and anchored on gold surfaces like AuNPs and Au(111) surfaces. To develop such a study, the structure of our target molecule was designed to have flexible chains to lead intramolecular collisions and hence spin exchange interactions, and with an appropriate disulfide binding group to be grafted on gold surfaces. In addition, quite long alkyl chains with 9 chemical bonds were employed to enhance the packing order of the molecules in the resulting self-assembled monolayers, and, finally, the ligand to stabilize the AuNPs were chosen with a similar number of chemical bonds in order to improve this packing, ${ }^{27}$ since several studies show that the greater the difference in chain lengths, the more favoured the phase segregation over the surface. ${ }^{28,29}$

\section{Results and Discussion}

\section{Synthesis}

The nitronyl nitroxide derivative $\mathbf{1}$ was synthesized according to Ullman's procedure ${ }^{30}$ as reported elsewhere with some modifications. This alcohol was condensed with 3,3'-dithiodipropionic acid by using DCC and DMAP ${ }^{31}$ to afford diradical 2 (66\% yield).

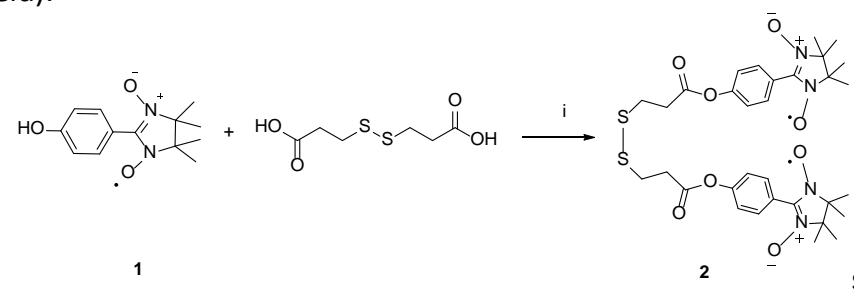

Scheme 1. Synthesis of nitronyl nitroxide disulfide 2. Reagents: (i) DCC, DMAP, $\mathrm{CH}_{2} \mathrm{Cl}_{2}$.

There are three main strategies reported to achieve NP functionalization: i) physisorption, ${ }^{32}$ ii) inclusion of hydrophobic radicals into water-soluble monolayer protected gold clusters, ${ }^{33,34}$ and iii) chemisorption based on the same sulfur-gold chemistry employed for flat surfaces. Chemically grafting molecules to surfaces is the most robust way to preserve hybrid organic-inorganic materials, which is superior to that of the assemblies obtained by physisorption. We have followed the latter strategy to graft diradical 2 to gold nanoparticles, following a ligand exchange reaction typically between the stabilizing ligands of the functionalized AuNPs and free ligands in solution. ${ }^{35,36,37}$

\section{Spin exchange in solutions of diradical 2}

The EPR spectrum of monoradical 1 (Fig. S1) shows five lines of relative intensities 1:2:3:2:1 due to the coupling of the unpaired electron with the two equivalent ${ }^{14} \mathrm{~N}$ atom which is invariant with the change of the temperature. In contrast, the EPR spectrum of diradical 2 shows nine lines (Fig. 1), indicating that there is a strong spin exchange interaction with $|J|>>\left|a_{(2 \mathrm{~N})}\right|$ between both nitronyl nitroxides units. The number of lines is invariant with the concentration (Fig. S2), however the spectrum changes upon cooling from 360 to $220 \mathrm{~K}$ along with a clear linewidth alternation. This result clearly shows that the intramolecular exchange interaction is modulated by the temperature.
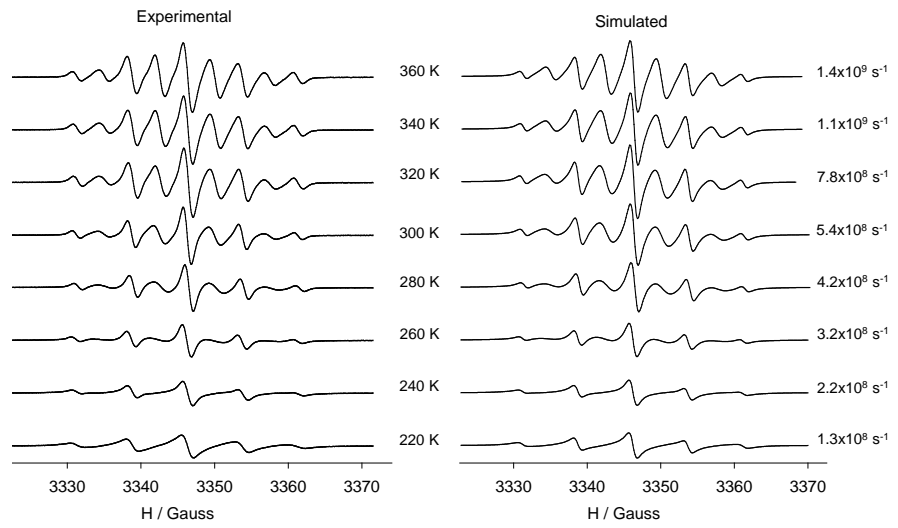

Fig. 1. EPR study of diradical 2 in toluene from 360 to $220 \mathrm{~K}$. 
In fact, in flexible diradicals like 2, magnetic exchange interactions $|J|$ may be not constant in solution because the radical units could be in movement under such conditions and critically depends on the frequency of collisions of the spin-bearing functional groups. ${ }^{38}$ Consequently, the EPR spectra should be dependent on the conformation and mobility of the two branches and therefore the shape of the spectra should be dependent on the temperature, viscosity and the nature of the solvent. In the case of a flexible $\mathrm{N}$-containing diradical, with only a through-space spin exchange mechanism between the two $\mathrm{N}$-radicals, we may have two limiting cases: a) When the two radicals are too far and the magnitude of $J$ is smaller than the hyperfine coupling constant with the 2 equivalent $N$ nuclei, $a_{(2 \mathrm{~N})}$, i.e. $|J| \ll\left|a_{(2 \mathrm{~N})}\right|$, ("far" conformation), the spectrum should be similar to that of two independent monoradicals exhibiting five lines separated by the hyperfine coupling constant $a_{(2 \mathrm{~N})}$ with relative intensities $1: 2: 3: 2: 1$; b) When the two radicals are closer and thereby $|J|>\left|a_{(2 \mathrm{~N})}\right|$ ("close" conformation), the spectrum should consist in nine lines with a separation of $a_{(2 \mathrm{~N})} / 2$ and relative intensities of 1:4:10:16:19:16:10:4:1.

Commonly, the EPR dynamic behaviour of most long-chain nitroxide dirradicals in liquid solutions with low viscosity has been so far described in terms of a three-conformation model (or the cage model), firstly proposed by Luckhurst ${ }^{39}$ and latter on further developed by Parmon et al. ${ }^{40}$ This model is necessary to explain the deviation of the relative intensities in the hyperfine pattern when the widths of all lines become equal. However, the spectra of diradical $\mathbf{2}$ in toluene are simpler and can be explained by the co-existence of just two conformations: one with $|J|>>\left|a_{(2 \mathrm{~N})}\right|$, and another one with $|J|<<\left|a_{(2 \mathrm{~N})}\right|$, with different rates of interconversion between them. This is the minimum number of effective conformations that is sufficient to reproduce the lineshape, corresponding to the two limiting cases described above. At $360 \mathrm{~K}$ (Fig. 1) the rate of interconversion is fast and hence the frequency of radical collisions is high. Under these conditions, the electron-spin exchange interaction is rapidly modulated and the alternating linewidth effect is less pronounced as we are close to the fast exchange limit $\left(|J|>>\left|a_{(2 \mathrm{~N})}\right|\right)$. As the temperature is gradually lowered from 360 to $220 \mathrm{~K}$, the alternate $\left(2^{\text {nd }}, 4^{\text {th }}, 6^{\text {th }}\right.$ and $\left.8^{\text {th }}\right)$ lines broaden and disappear. At low temperatures, molecular motions slow down and hence the rate of interconversion between effective conformations becomes slow. At $220 \mathrm{~K}$ the frequency of collisions is very low and the spectrum is not affected by spin exchange interactions (slow exchange limit, $\left.|J|<<\left|a_{(2 \mathrm{~N})}\right|\right)$ showing only five lines with 1:2:3:2:1 relative intensities.

First-order rate constants for the thermally activated process were extracted by fitting the experimental EPR spectra at each temperature using a two-conformation model from the Quantum Chemistry Program Exchange package ${ }^{41,42}$ (Fig. 1). These rate constants were fitted to a linear Arrhenius plot, over the 220-360 K temperature range (see Fig. S3), giving the activation

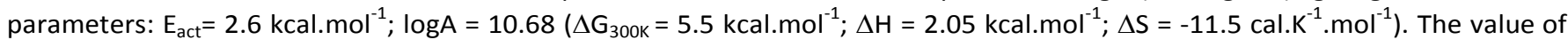
$\Delta \mathrm{H}$ is positive, which means that the transition from the "far" to the "close" conformation is endothermic and hence, the conformation in which radicals do not interact ("far" conformation) is consequently the most stable one.

In frozen conditions the spectrum obtained (Fig. 2) shows the typical EPR pattern of a monoradical phenyl nitronyl nitroxide in such conditions. ${ }^{43}$ Thus, no appreciable dipolar interactions are detected in this diradical. Besides, no $\left|\Delta m_{s}\right|=2$ transition at halffield was observed in dilution conditions (Fig. S4) confirming the no existence of dipolar coupled spins. However, we observed weak transition bands at half-field at very high concentrations $\left(10^{-2} \mathrm{M}\right.$ and $5 \times 10^{-3} \mathrm{M}$, see Fig. S4) which come from intermolecular interactions. ${ }^{7 i}$

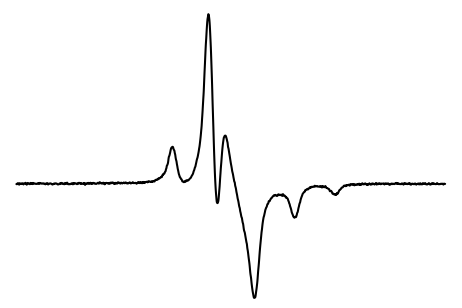

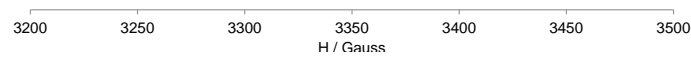

Fig. 2. EPR spectrum of diradical $\mathbf{2}$ in dichloromethane/toluene at $120 \mathrm{~K}$.

Cyclic voltammetry $(\mathrm{CV})$ of diradical 2 was carried out in $\mathrm{CH}_{3} \mathrm{CN}$ with $0.02 \mathrm{M}$ of tetrabutylammonium hexafluorophosphate as electrolyte and using $\mathrm{Pt}_{\mathrm{s}}$ as working electrode. The cyclic voltammogram showed one reversible redox wave at $E_{1 / 2}=0.23 \mathrm{~V}$ (Fig. 3) with a difference between the anodic and cathodic peaks of $\Delta \mathrm{E}=110 \mathrm{mV}$. This electrochemically quasi-reversible process corresponds to two-electron oxidation process of the two nitronyl nitroxide moieties. This result suggests the presence of a very weak or negligible electronic interaction between the radical units, since in the case of a strong or moderate electronic interaction between the two units, two electrochemical waves would be anticipated. 


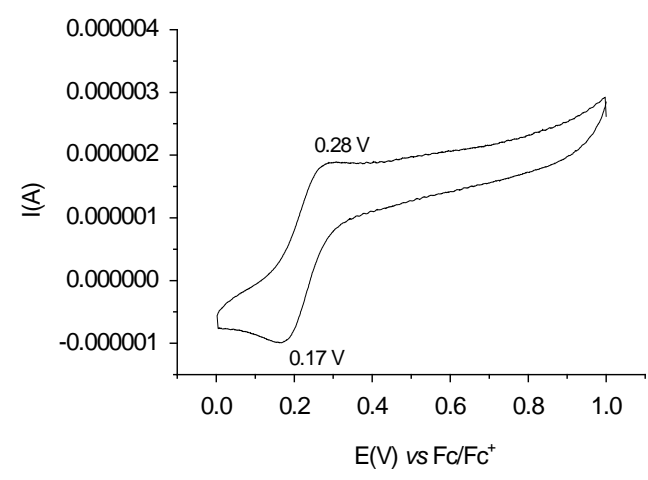

Fig. 3. Cyclic voltammogram of diradical 2 in $\mathrm{CH}_{3} \mathrm{CN}$ with $0.02 \mathrm{M}$ of $n-\mathrm{Bu}_{4} \mathrm{NPF}_{6}$ at $100 \mathrm{mV} / \mathrm{s}$.

\section{Diradical 2 anchored on AuNPs}

To go a step forward we studied the possibility of preserving the same behaviour observed in solution in surface-anchored radicals. Chechik et al. reported that the two branches of a disulfide molecule do not adsorb adjacent to each other on the Au surface. ${ }^{19}$ However, to observe spin exchange interactions they should be in close proximity. Thus, high density of radicals on the nanoparticle surface is required. In a previous work we published the best conditions to obtain Au nanoparticles with a very high coverage of TEMPO radicals, using one-pot reaction and at room temperature. ${ }^{36}$ In that method, we first synthesized Au nanoparticles through the chemical reduction of $\mathrm{HAuCl}_{4}$ with $\mathrm{NaBH}_{4}$ in the presence of tri- $n$-octylamine as stabilizer and then, in the same batch, we performed the ligand exchange reaction with large excess of a disulfide functionalized with two TEMPO radicals. Finally, the reaction was let stirring overnight at room temperature. The solution EPR spectrum of the resulting purified nanoparticles showed an intense single broad line expected for high amount of interacting radicals, indicating that the coverage was very high. We repeated the same conditions of the synthesis with the analogous disulfide functionalized with the nitronyl nitroxide (2). However, the obtained AuNPs (3, Scheme S1) presented low coverage of a mixture of radicals. In fact, the solution EPR spectrum (Fig. S5) did not show any single broad line but only narrow lines. The number of lines indicated the presence of two different radicals: the nitronyl nitroxide and the imino nitroxide, ${ }^{44}$ being the latter the most abundant one (Fig. S5).

In order to eliminate or reduce to the minimum amount the formation of imino nitroxide increasing the coverage of nitronyl nitroxide radicals, we decided to remove the $\mathrm{NaBH}_{4}$ from the media before performing the ligand exchange reaction. Thus, once

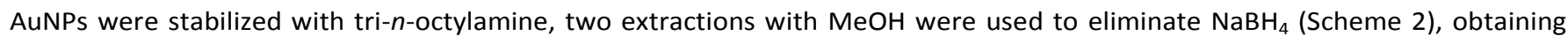
good results.

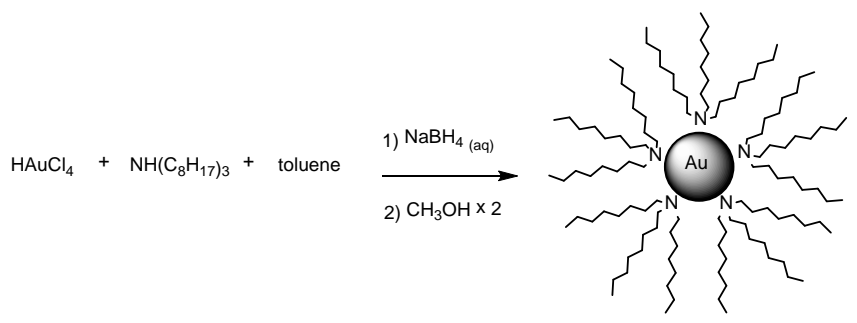

Scheme 2. Formation of AuNPs stabilized with tri-n-octylamine.

To the toluene solution containing the stabilized "clean" nanoparticles we added the solution of diradical $\mathbf{2}$ in dichloromethane and then stirred the mixture overnight at room temperature as in the above mentioned reference reaction. However, the corresponding solution EPR spectrum of the purified nanoparticles (4) showed little intense five lines with no contribution of any broad line (Fig. 4), corresponding to low spin label coverage with no appreciable interactions between the radicals adsorbed on the same nanoparticle. For this reason, we proceeded to optimize the ligand exchange reaction playing with different factors such as the temperature, reaction time, atmosphere and agitation of the solution. The coverage was increased (AuNPs $\mathbf{5}$ and $\mathbf{6}$, Figure 4) until obtaining the final goal (AuNPs 7, Figure 4). For reaction conditions and characterization of AuNPs 5 and 6 see Schemes S2 and S3 and Figs. 6-8 in the ESI.

The best conditions (AuNPs 7) were obtained performing the ligand exchange reaction heating the AuNPs stabilized by tri- $n$ octylamine with the excess of diradical 2 at $40 \circ \mathrm{C}$ for $4 \mathrm{~h}$ and $30 \mathrm{~min}$, under argon atmosphere and uniformly stirring the solution using paddles (Scheme 3). The obtained NPs were characterized by EPR, UV-Vis and IR spectroscopies, TEM microscopy, Cyclic Voltammetry, Energy Dispersive X-ray analysis (EDX), and Thermogravimetric Analysis (TGA).

In this case, we obtained the desired goal as the nanoparticles exhibited an intense single broad line overlapping the EPR spectrum lines (Fig. 4) indicating high coverage of nitronyl nitroxide radicals and high interactions between the radicals adsorbed 
on the same particle. In addition, it is worth saying that the reaction was reproducible as we always obtained similar shape of the EPR spectra.

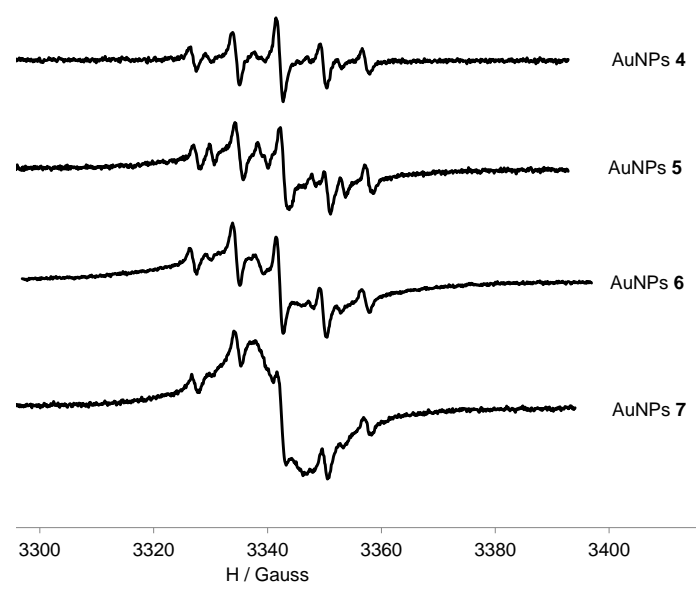

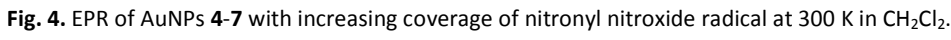

The UV-Vis spectrum (Scheme 3, Fig. b) showed a weak plasmon peak (shoulder at around $530 \mathrm{~nm}$ ) indicating the formation of quite small nanoparticles. ${ }^{45,46}$ The shape and position of this band was in agreement with previously reported particles of ca. 2$\mathrm{nm}$ diameter synthesized by the two-phase method. ${ }^{47,48}$ In fact, we obtained homogeneous and quite well dispersed gold nanoparticles with a diameter of $2.06 \pm 0.27 \mathrm{~nm}$, (HR-TEM pictures of Scheme 3). The Thermogravimetric Analysis (TGA) of these NPs showed that $83.42 \%$ of the total mass of nanoparticles was organic coating (Fig. S9). From these data and TEM analysis we could estimate the maximum number of radicals per nanoparticle possible and the packing density (see the ESI). These values are very high, however, it is important to note that, by one hand, indicate much more radicals anchored on the AuNPs surface than in AuNPs 6 (see ESI), and hence more coverage, which is in agreement with the experimental EPR spectra shape obtained. And, on the other hand, are in accord with previously reported values for densely coated NP with TEMPO radicals. ${ }^{36}$ This result, thus, supports the ones extracted by EPR. In fact, the shape of the EPR spectra is very sensitive to the radical-radical interactions and these are directly related to the packing density. Therefore, a qualitative but unequivocally way to distinguish the packing density is to use the EPR spectroscopy, ${ }^{35,36}$ a powerful tool to study spin labeled Au NPs. ${ }^{49}$ EDX spectrum confirmed the presence of S-ligands and the presence of nitrogen atoms in the NPs 7 (see Fig. S10) and the IR spectrum is shown in Fig. S11.

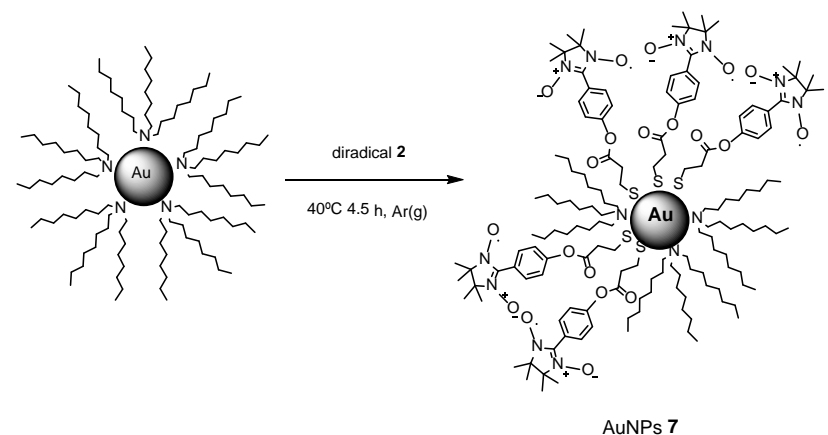

AuNPs 7 


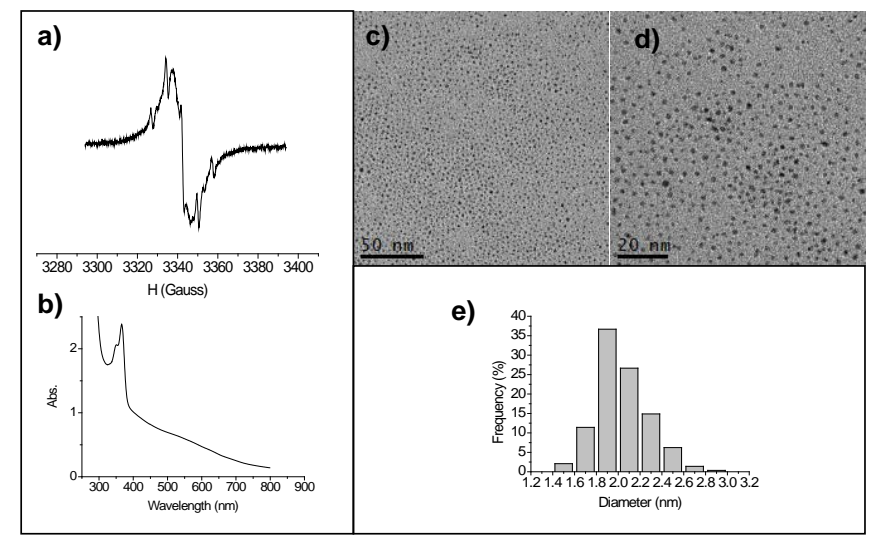

Scheme 3. Up) Ligand exchange reaction to obtain AuNPs 7. Down) Characterization of nanoparticles AuNPs 7: (a) Solution EPR spectrum. (b) UV-Vis spectrum. (c) and (d) HR-TEM pictures. (e) Core size distribution histograms (average $2.06 \pm 0.27 \mathrm{~nm}$ ).

These nanoparticles were studied by variable-temperature EPR. EPR spectra of a dichloromethane solution of AuNPs 7 were recorded from $300 \mathrm{~K}$ to $220 \mathrm{~K}$ (Fig. 5). As we had high coverage of radicals they were very close to each other, leading to dipolar and spin exchange interactions between adjacent radicals adsorbed on the same nanoparticle. For this reason, the spectrum at $300 \mathrm{~K}$ showed an intense single broad line. This broad line was overlapping a nine-line spectrum with alternate lines, like diradical $\mathbf{2}$ in solution. This spectrum contribution comes from the strong spin exchange interaction $|J|>>\left|a_{(2 \mathrm{~N})}\right|$ between, mainly, pairs of two close nitronyl nitroxides radical units anchored on the AuNP surface. As the temperature decreases, the alternate $\left(2^{\text {nd }}, 4^{\text {th }}, 6^{\text {th }}\right.$ and $\left.8^{\text {th }}\right)$ lines broaden and disappear like in solution. At $220 \mathrm{~K}$ the spectrum shows only five narrow lines, with some contribution of the single broad line, because although at this temperature the spectrum is less affected by spin exchange interactions it is sensitive to dipole-dipole interactions. Dipole-dipole interactions are dependent on radical-radical distances and produce a broadening of the EPR lines. Upon heating back to room temperature, the original spectrum was restored. Considering the above, we can say that the behaviour observed in the surface-confined radicals is similar to the intramolecular spin exchange dynamic behaviour of diradical $\mathbf{2}$ in solution. Thus, we can affirm that it is possible to preserve the same dynamic behaviour observed in solution in surface-anchored radicals.

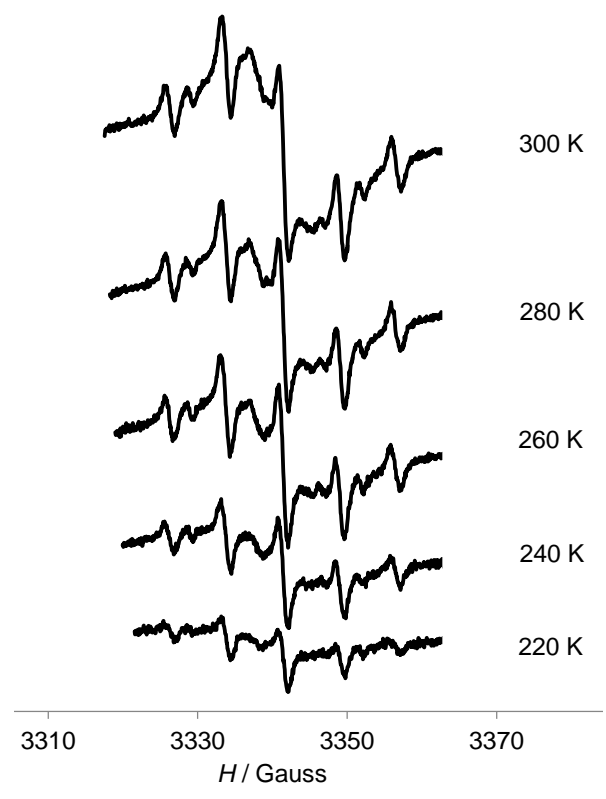

Fig. 5. EPR temperature study of AuNPs 7 in dichloromethane from 300 to $220 \mathrm{~K}$.

It's interesting to note that the EPR spectra have narrow and quite symmetric lines, characteristic of the so-called "fast rotation" regime of the nitroxide label. ${ }^{35}$ This could be explained because the chain connecting the nitronyl nitroxide to the surface is slightly longer than the surrounding ligand and hence the motion of the spin label is least hindered. In fact, in gold nanoparticles highly covered with TEMPO radicals ${ }^{36}$ with similar length between the chains connecting the radicals to the surface and the surrounding ligand there was almost no spectral resolution. The motion of a surface-attached functional group crucially depends on the nature of the linker and the packing of a surrounding monolayer. 
The EPR spectrum of AuNPs 7 in frozen conditions showed only one single broad line $\left(\Delta \mathrm{H}_{\mathrm{pp}}=20.3 \mathrm{G}\right.$, Fig. 6$)$ instead of the typical EPR spectrum pattern of a frozen phenyl nitronyl nitroxide monoradical, ${ }^{43}$ demonstrating that dipolar interactions are detected between the radicals attached on the nanoparticles surface, averaged over a large distribution of distances. Under these conditions, an $\left|\Delta m_{s}\right|=2$ transition at half-field was detected (inset of Fig. 6), confirming the dipolar interactions. This forbidden transition gives direct evidence for the presence of a high-spin state in this system and, on the other hand, permits to study the nature of the magnetic coupling between spins. It is worth mentioning that diradical 2 did not show $\left|\Delta m_{s}\right|=2$ transition at halffield in frozen solution (only at very high concentrations). This means that the distance between nitronyl nitroxides anchored on the NP is closer than in the diradical, which is in agreement with the high coverage (or packing density) of the AuNPs previously estimated.

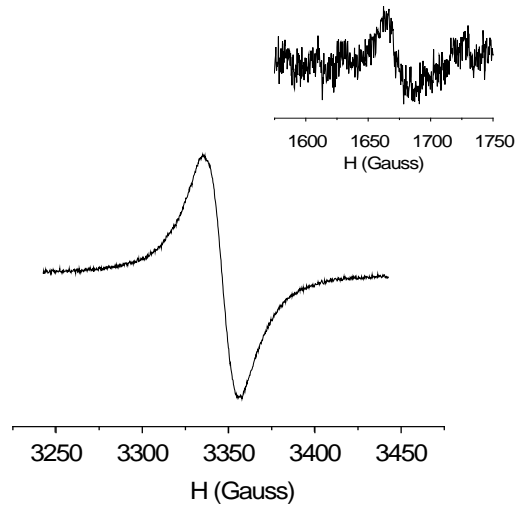

Fig. 6. EPR spectrum of AuNPs 7 in dichloromethane, recorded at $140 \mathrm{~K}$. Inset shows the $\left|\Delta m_{\mathrm{s}}\right|=2$ transition at half-field.

The usual way to study magnetic interactions in a paramagnetic compound is to undertake a SQUID magnetometry study. Unfortunately, to perform an experiment by SQUID high amount of sample is needed especially in samples with low spin density as in the case of organic radicals. However, we can make a semi-quantitative assessment of the magnetic interactions that take place in the nanoparticle by EPR technique. The intensity (double integral) of the $\left|\Delta m_{s}\right|=2$ half-field transition EPR signal is proportional to the imaginary part of the magnetic susceptibility. ${ }^{50}$ Therefore, the plot of $I \cdot T$ vs. $T$ (where $I$ is the spectrum intensity of the $\left|\Delta m_{\mathrm{s}}\right|=2$ transition) shows the same shape of the curve as in the usual representation of $\chi \cdot T$ vs. $T$ as measured by SQUID. $9^{\mathrm{e}, 10,51}$ According to the shape of the curve obtained, we can assess the type of predominant magnetic interactions in the sample.

The intensity of the $\left|\Delta m_{\mathrm{s}}\right|=2$ transition signal $(I)$ was measured in the 4-80 K temperature region and the corresponding $I \cdot T$ vs. $T$ for nanoparticles $\mathbf{7}$ is shown in Fig. 7. We can observe that there is a monotonical decrease of the $I \cdot T$ value as the temperature decreases, indicating predominant antiferromagnetic interactions among the spin carriers of the nanoparticles.

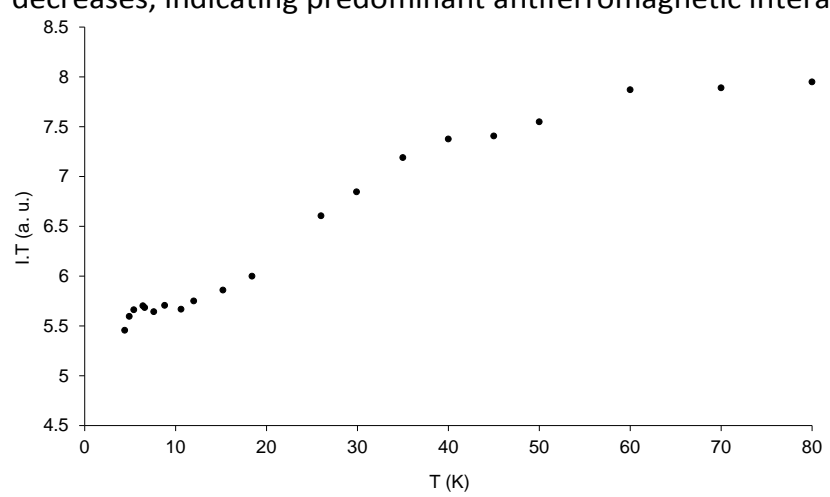

Fig. 7. Dependence of the intensity of AuNP 7 half-field transition band $\left|\Delta m_{s}\right|=2$ with temperature.

The electrochemical properties of gold nanoparticles AuNPs 7 were studied by Cyclic Voltametry (CV). The CV was carried out in $\mathrm{CH}_{3} \mathrm{CN}$ with $0.02 \mathrm{M}$ of tetrabutylammonium hexafluorophosphate as electrolyte and using $\mathrm{Pt}_{\mathrm{s}}$ as working electrode. The cyclic voltammogram (Fig. 8a) showed one reversible redox wave with an anodic peak at $0.30 \mathrm{~V}$ and a cathodic peak at $0.28 \mathrm{~V}$, at 100 $\mathrm{mV} / \mathrm{s}$, attributable to nitronyl nitroxides on nanoparticles surface. The voltage difference between the anodic and cathodic peaks $(\Delta \mathrm{E}=20 \mathrm{mV})$ is $90 \mathrm{mV}$ smaller than the value obtained for disulfide $\mathbf{2}$ in solution $(\Delta \mathrm{E}=110 \mathrm{mV})$. This is an additional indication that the electroactive molecules are adsorbed on the gold nanoparticles surface and indicates that the diffusion process seems to be very fast. Although we observed a very small value of $\Delta \mathrm{E}$, it would be expected no splitting between the oxidation and 
reduction peaks for an ideal situation. ${ }^{52}$ Such peak splitting could be explained by the interaction between nitronyl nitroxides moieties. We also observed that increasing the scan rate resulted in an increase in the intensity of the peaks (Fig. 8b), which is characteristic for surface-confined electroactive species. The stability of these nanoparticles was elucidated by the reversibility of the process and the fact that after applying several redox cycles the response was unilateral.

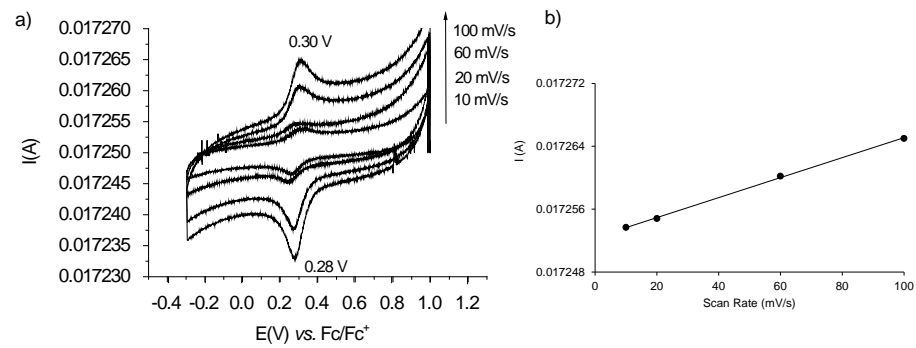

Fig. 8. a) Cyclic voltammograms of AuNPs 7 in $\mathrm{CH}_{3} \mathrm{CN}$ with $0.02 \mathrm{M}$ of $n-\mathrm{Bu}_{4} \mathrm{NPF}_{6}$ at different scan rates $10,20,60,100 \mathrm{mV} / \mathrm{s}$. b) Plot of the current intensity vs scan rate.

\section{Diradical 2 anchored on flat $\mathrm{Au}(\mathbf{1 1 1})$ surfaces}

Once studied the behaviour of diradical $\mathbf{2}$ anchored on Au NPs dissolved in solution, we studied the properties of the same diradical anchored on a gold planar surface in the solid state. Disulfide $\mathbf{2}$ chemisorbed on a Au(111) substrate by preparing selfassembled monolayers (SAMs). ${ }^{53}$ For this purpose the approach used was the direct anchoring of the disulfide functionalized with nitronyl nitroxide radicals on the gold surface. The preparation of the SAMs was achieved by immersing a freshly clean gold substrate in a $1 \mathrm{nM}$ THF solution of diradical 2 under argon atmosphere for $3 \mathrm{~h}$ at 40 으 $\mathrm{C}$ and then during $10 \mathrm{~h}$ at room temperature. After this time the monolayer was vigorously rinsed with abundant THF, to ensure that there was no physisorbed material on the substrate and dried under a $\mathrm{N}_{2}$ stream (Scheme 4). The SAMs were characterized by contact angle, X-Ray Photoelectron Spectroscopy (XPS), and time-of-flight secondary ion mass spectroscopy (ToF-SIMS). The electrochemical and magnetic properties of these SAMs were investigated by Cyclic Voltammetry (CV) and EPR, respectively.

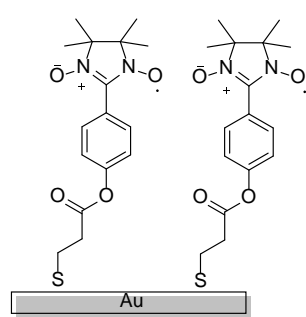

Scheme 4. Scheme of the SAM of nitronyl nitroxide derivative 2 on $\mathrm{Au}(111)$

Contact angle value was $78.6 \pm 2 \circ$, showing the high hydrophobicity of the layer. The XPS spectrum of the SAM showed two doublets assigned to S2p (Fig. S12 of the ESI). One at 162.3 and $163.5 \mathrm{eV}$, assigned to S2 $\mathrm{p}_{3 / 2}$ and S2 $\mathrm{p}_{1 / 2}$ respectively, with an intensity ratio of $1.9: 1$ (very close to the expected value of $2: 1$ ) and a splitting of $1.2 \mathrm{eV}^{54}$ attributed to the $\mathrm{S}-\mathrm{Au}$ bond and the other at a 161.3 and $162.5 \mathrm{eV}$, assigned to $\mathrm{S} 2 \mathrm{p}_{3 / 2}$ and $\mathrm{S} 2 \mathrm{p}_{1 / 2}$ respectively, with the same intensity ratio and splitting than the first one. It could be attributed to a disulfide group -S-S-Au, to the different state of $\mathrm{S}$ bond on the Au(111) caused by the organization constraints in the SAM ${ }^{55,56}$ or to atomic sulfur generated by $\mathrm{S}-\mathrm{C}$ bond scission during irradiation. ${ }^{57}$ Additionally, Time-of-Flight Secondary Ion Mass Spectrometry (ToF-SIMS) was performed (Figs. S13 and S14 of the ESI). We observed the peak corresponding to the molecular ion peak $\left(\mathrm{M}^{+}\right)$for $\mathrm{SC}_{12} \mathrm{H}_{21} \mathrm{~N}_{2} \mathrm{O}_{2}$ at $336.4 \mathrm{~m} / z$ and a peak corresponding to a $\mathrm{S}-\mathrm{SC}_{12} \mathrm{H}_{21} \mathrm{~N}_{2} \mathrm{O}_{2}\left(\mathrm{~S}-\mathrm{M}^{+}\right)$ at $368.4 \mathrm{~m} / \mathrm{z}$, verifying the adsorption and integrity of the molecules.

Cyclic Voltammetry of AuNPs 7 was carried out in $\mathrm{CH}_{3} \mathrm{CN}$ with $0.02 \mathrm{M}$ of tetrabutylammonium hexafluorophosphate as electrolyte and using the functionalized gold substrate (SAM) as working electrode. The cyclic voltammogram showed one reversible redox wave with an anodic peak at $0.24 \mathrm{~V}$ and a cathodic peak at $0.22 \mathrm{~V}$, at $100 \mathrm{mV} / \mathrm{s}$, attributable to nitronyl nitroxides on surface (Fig. 9a). The $\Delta \mathrm{E}$ between peaks $(\Delta \mathrm{E}=20 \mathrm{mV})$ is as small as in AuNP 7 , also confirming that radicals are anchored on the $\mathrm{Au}(111)$ surface and indicates that the diffusion process seems to be very fast. This splitting could be explained by the interaction between nitronyl nitroxides moieties, as previously explained for AuNPs 7. We also observed that increasing the scan rate resulted in an increase in the intensity of the peaks (Fig. 9b), which is characteristic for surface-confined electroactive species. By performing many consecutive voltage cycles, completely identical redox waves without showing any sign of loss of current intensity were observed, indicating that the two redox states are stable. 


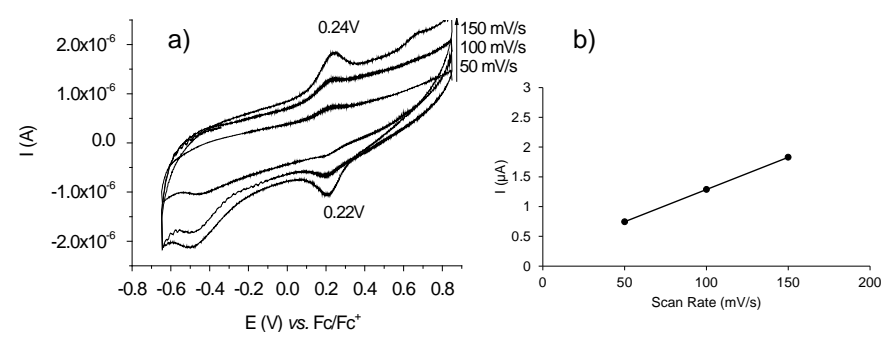

Fig. 9. a) Cyclic voltammograms of the $\mathrm{SAM}$ in $\mathrm{CH}_{3} \mathrm{CN}$ with $0.02 \mathrm{M} \mathrm{n}-\mathrm{Bu}_{4} \mathrm{NPF}_{6}$ at different scan rates $(50,100$ and $150 \mathrm{mV} / \mathrm{s})$. b) Plot of the current intensity vs scan rate.

The EPR spectrum further confirmed that the radical character was preserved since a signal at $g$-value and linewidth of 2.0078 and $9.4 \mathrm{G}$ respectively was observed (Fig. 10b). We observed a single broad line due to large electron dipole-dipole and spin exchange interactions between neighbouring surface-anchored radicals, which is expected for a densely packed 2D array of nitronyl nitroxide radicals, revealing thus high coverage. However, Gatteschi et al. anchored a series of $\alpha$-nitronyl nitroxyls derivatives with a methylthio surface anchoring group to gold surface and observed EPR signals with hyperfine structure coming from the coupling of the unpaired electron with the two equivalent ${ }^{14} \mathrm{~N}$ nuclei (i.e. five lines). ${ }^{22,26}$ The quasi-isotropic motion of the radicals indicated quite a large mobility of the radicals grafted to the surface and hence low packing density of the radicals. We only barely detect some of the EPR lines (marked with asterisks in the spectrum, Fig. 10b) presumably because of the much higher packing density achieved in this case. If we compare this signal with the one obtained for gold nanoparticles 7 of the best coverage batch in solution at $300 \mathrm{~K}\left(g=2.0060\right.$ and $\Delta \mathrm{H}_{\mathrm{PP}}=10.1 \mathrm{G}$, Fig. 10a) we can observe that the two spectra have very similar narrow linewidth of the single line. The linewidth of exchange-narrowed EPR spectra is sensitive to the distance between adjacent labels, e.g., their packing density. ${ }^{35}$ At high coverage and tight packing of spin labels the line becomes narrower. ${ }^{58}$ The linewidth observed in the EPR of gold nanoparticles is slightly higher than in the SAM on Au(111) which indicates slightly lower packing density in the AuNPs, probably mostly due to the curvature of the 3D gold NP. However, this difference in linewidth is very small indicating that both systems show high and very similar coverage.

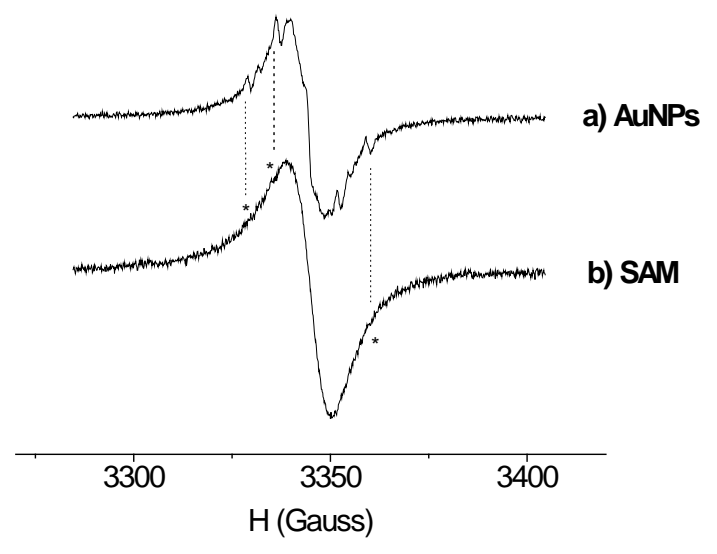

Fig. 10. a) EPR spectrum of AuNPs 7 of the best coverage batch at $300 \mathrm{~K}$ in dichloromethane. b) EPR spectrum of the SAM on Au(111) in the solid state.

\section{Summary and Conclusions}

A novel diradical nitronyl nitroxide-substituted disulfide has been synthesized and characterized. In solution, this diradical shows a strong spin exchange interaction between both radicals which is modulated by the temperature. We have also shown that it is possible to obtain gold nanoparticles functionalized with a high coverage of nitronyl nitroxide radical showing also such phenomenon, preserving the same behaviour observed in solution. This result has significant importance for developing functional hybrid surfaces and opens the possibility to be used as a new class of spin markers, for studying the dynamics of biological systems, for MRI applications or, as new materials for nanoparticles based spintronics. ${ }^{18}$ The $\left|\Delta m_{s}\right|=2$ transition at half-field signal that present these nanoparticles has permitted us to study by EPR the nature of the magnetic coupling between the spins, being antiferromagnetic.

The same disulfide was also used to functionalize flat gold surface as a SAM and EPR and CV studies showed analogies between these two different kinds of multifunctional surfaces. 


\section{Acknowledgements}

This work was supported by CSIC-PIF RAPCAM (PIF-08-017-3), the DGI grants CONSOLIDERC (CTQ2006-06333) and POMAs (CTQ2010-19501), and AGAUR (2009-SGR-00516). CIBER-BBN is an initiative funded by the VI National R\&D\&i Plan 2008-2011, Iniciativa Ingenio 2010, Consolider Program, CIBER Actions and financed by the Instituto de Salud Carlos III with assistance from the European Regional Development Fund.

TOC

TOC

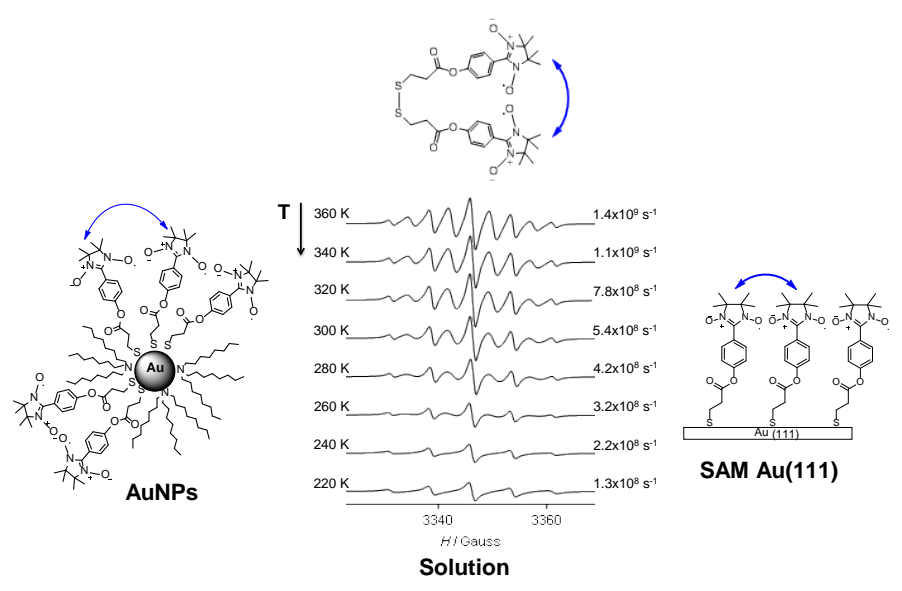

It is possible to preserve the same dynamic behaviour observed for a diradical in solution in AuNPs surface-anchored radicals.

\section{Notes and references}

1 a) E. A. Weiss, M. J. Ahrens, L. E. Sinks, A. V. Gusev, M. A. Ratner and M. R. Wasielewski, J. Am. Chem. Soc., 2004, 126, 5577-5584; b) E. A. Weiss, M. J. Tauber, R. F. Kelley, M. J. Ahrens, M. A. Ratner and M. R. Wasielewski, J. Am. Chem. Soc., 2005, 127, 11842-11850; c) E. T. Chernick, Q. Mi, R. F. Kelley, E. A. Weiss, B. A. Jones, T. J. Marks, M. A. Ratner and M. R. Wasielewski, J. Am. Chem. Soc. 2006, 128, 4356-4364; d) E. Gomar-Nadal, L. Múgica, J. Vidal-Gancedo, J. Casado, J. T. López Navarrete, J. Veciana,

C. Rovira and D. B. Amabilino, Macromolecules, 2007, 40, 7521-7531.

2 a) H. Iwamura and N. Koga, Acc. Chem. Res., 1993, 26, 346-351; b) P. Ferruti, D. Gill, M. P. Klein, H. H. Wang, G. Entine and M. Calvin, J. Am. Chem. Soc., 1970, 92, 3704-3713; c) A. Rajca, Adv. Phys. Org. Chem., 2005, 40, 153-199; d) P. M. Lahti in Magnetic Properties of Organic Materials; Ed.; Marcel Dekker: New York, 1999; pp 1-713; e) K. Itoh and M. Kinoshita in Molecular Magnetism; Eds.; Kodansha: Tokyo, 2000; pp 1-337; f) D. Gatteschi, O. Kahn, J. S. Miller and F. Palacio, Magnetic Molecular Materials, Eds.; NATO ASI Series; Kluwer Academic Publishers: Dordrecht, 1991; g) K. Yamaguchi, M. Okumura, J. Maki, T. Noro, H. Namimoto, M. Nakano, T. Fueno and K. Nakasuji, Chem. Phys. Lett., 1992, 190, 353-360; h) A. Rajca, Chem.-Eur. J., 2002, 8, 4834-4841; i) D. Maspoch, D. Ruiz-Molina, K. Wurst, J. Vidal-Gancedo, C. Rovira and J. Veciana, Dalton Trans., 2004, 7, 1073-1082; j) V. Barone, A. Bencini and A. di Matteo J. Am. Chem. Soc., 1997, 119, 10831-10837; k) J. Fritscher, M. Beyer and O. Schiemann, Chem. Phys. Lett., 2002, 364, $393-401$.

3 a) A. Rajca, J. Wongsriratanakul and S. Rajca, Science, 2001, 294, 1503-1505; b) A. Rajca, K. Shiraishi, M. Vale, H. Han and S. Rajca, J. Am. Chem. Soc., 2005, 127, 9014-9020; c) S. Rajca, A. Rajca, J. Wongsriratanakul, P. Butler and S. Choi, J. Am. Chem. Soc., 2004, 126, $6972-6986$.

4 E. Fukuzaki and H. Nishide, J. Am. Chem. Soc., 2006, 128, 996-1001.

5 a) E. J. Hustedt and A. H. Beth, Annu. Rev. Biophys. Biomol. Struct., 1999, 28, 129-153; b) S. S. Eaton and G. R. Eaton, Biol. Magn. Reson., 2000, 19, 1-27; c) C. Altenbach, K. J. Oh, R. Trabanino, K. Hideg and W. Hubbell, Biochemistry, 2001, 40, 15471-15482; d) P. Hanson, G. Millhauser, F. Formaggio, M. Crisma and C. Toniolo, J. Am. Chem. Soc., 1996, 118, 7618-7625.

6 a) H. Sato, V. Kathirrvelu, G. Spagnol, S. Rajca, A. Rajca, S. S. Eaton and G. R. Eaton, J. Phys. Chem. B, 2008, 112, 2818-2828; b) A. Rajca, S. Mukherjee, M. Pink and S. Rajca, J. Am. Chem. Soc., 2006, 128, 13497-13507.

7 a) S. Sankarapandi, J. M. Rifkind and P. T. Manoharan, Proc.- Indian Acad. Sci., Chem. Sci., 1994, 106, 1329-1340; b) N. J. Turro, I. V. Khurdyakov, S. H. Bossmann and D. W. Dwyer, J. Phys. Chem., 1993, 97, 1138-1146; c) C. Corvaja, M. de Narchi and A. Toffoletti, Appl. Magn. Reson., 1997, 12, 1; d) E. Alster and B. L. Silver, Mol. Phys., 1986, 58, 977; e) A. I. Kokorin, V. A. Tran, K. Rasmussen and G. Grampp, Appl. Magn. Reson., 2006, 30, 35-42; f) V. N. Tran, K. Rasmussen, G. Grampp and A. I. Kokorin, Appl. Magn. Reson., 2007, 32, 395-406; g) C. Casati, P. Franchi, R. Pievo, E. Mezzina and M. Lucarini, J. Am. Chem. Soc., 2012, 134, 19108-19117; h) M. F. Ottaviani, A. Modelli, O. Zeika, S. Jockusch, A. Moscatelli and N. J. Turro, J. Phys. Chem. A, 2012, 116, 174-184; i) V. Lloveras, E. Badetti, K. Wurst and J. Vidal-Gancedo, ChemPhysChem, 2015, 16, 3302-3307.

8 a) A. W. Bosman, R. A. J. Janssen and E. W. Meijer, Macromolecules, 1997, 30, 3606-3611; b) E. Badetti, V. Lloveras, K. Wurst, R. M. Sebastián, A.-M. Caminade, J.-P. Majoral, J. Veciana and J. Vidal-Gancedo, Org. Lett., 2013, 14, 3490-3493; c) E. Badetti, V. Lloveras, J. L. Muñoz-Gómez, R. M. Sebastián, A.-M. Caminade, J.-P. Majoral, J. Veciana and J. Vidal-Gancedo, Macromolecules, 2014, 47, 7717-7724.

9 a) D. Zhang, Y. Xu, L. Ding, Y. Liu and D. Zhu, Chem. Phys. Lett., 1999, 304, 236-240; b) T. Mitsumori, K. Inoue, N. Koga and H. Iwamura, J. Am. Chem. Soc., 1995,117, 2467-2478; c) H. Tanaka, T. Ise , D. Shloml, K. Sato and T. Takui, J. Low Temp. Phys., 2006, 142, 601-604; d) Md. E. Ali and S. N. Datta, J. Phys. Chem. A, 2006, 110, 2776-2784; e) G. Zoppellaro, A. Ivanova, V. Enkelmann, A. Geies and M. Baumgarten, Polyhedron, 2003, 22, 2099-2110; f) N. Tanifuji, K. Matsuda and M. Irie, Polyhedron, 2005, 24, 2484-2490; g) A. Rajca, M. Pink, S. Mukherjee, S. Rajca and K. Das, Tetrahedron, 2007, 63, 10731-10742; h) T. Akita, Y. Mazaki and K. Kobayashi, Tetrahedron Lett., 1995, 36, 5543-5546.

10 N. L. Frank, R. Cle'rac, J.-P. Sutter, N. Daro, O. Kahn, C. Coulon, M. T. Green, S. Golhen and L. Ouahab, J. Am. Chem. Soc., 2000, 122, 2053-2061. 
11 L. Pasquato, P. Pengo and P. Scrimin, J. Mater. Chem., 2004, 14, 3481-3487.

12 E. C. Dreaden, A. M. Alkilany, X. Huang, C. J. Murphy and M. A. El-Sayed, Chem. Soc. Rev., 2012, 41, 2740-2779.

13 E. Boisselier and D. Astruc, Chem. Soc. Rev., 2009, 38, 1759-1782.

14 a) A. De La Escosura-Muniz, C. Sánchez-Espinel, B. Díaz-Freitas, A. González-Fernández, M. Maltez-da Costa and A. Merkozi, Anal. Chem., 2009, 81, 1026810274; b) A. Llevot and D. Astruc, Chem. Soc. Rev., 2012, 41, 242-257; c) X. Huag, K. J. Prashant, I. H. El-Sayed and M. A. El-Sayed, Nanomedicine, 2007, 2, 681-693.

15 O. Swiech, R. Bilewicz and E. Megiel, RSC Adv., 2013, 3, 5979-5986.

16 V. Caps, Actual. Chim., 2010, 337, 18-22.

17 X. Wang and O. Ramstroem, M. A. Yan, J. Mater. Chem., 2009, 19, 8944-8949.

18 T. Sugawara and M. M. Matsushit, J. Mater. Chem., 2009, 19, 1738-1753.

19 P. Ionita, A. Caragheorgheopl, B. C. Gilbert and V. Chechik, J. Am. Chem. Soc., 2002, 124, 9048-9049.

20 a) Templeton, A. C.; Hostetler, M. J.; Warmoth, E. K.; Chen, S.; Hartshorn, C. M.; Krishnamurthy, V. M.; Forbes, M. D. E.; Murray, R. W., J. Am. Chem. Soc., 1998, 120, 4845-4849; b) lonita P., Caragheorgheopol A., Gilbert B.C., Chechik V., J. Phys. Chem. B, 2005, 109, 3734-3742; c) lonita, P.; Volkov, A.; Jeschke, G.; Chechik, V., Anal. Chem., 2008, 80, 95-106; d) Zachary, M.; Chechik, V., Angew. Chem. Int. Ed., 2007, 46, 3304-3307; e) Kaim, A.; Szydlowska, J.; Piotrowski, P.; Megiel, E., Polyhedron, 2012, 46, 119-123; f) Nagasaki, Y., Therapeutic delivery, 2012, 3, 1-15; g) Harada, G.; Sakurai, H.; Matsushita, M.; Izuoka, A.; Sugawara, T., Chem. Lett., 2002, 31, 1030-1031.

21 F. Busolo, L. Franco, L. Armelao, M. Maggini, Langmuir, 2010, 26, 1889

22 M. Mannini, L. Sorace, L. Gorini, F. M. Piras, A. Caneschi, A. Magnani, S. Menichetti and D. Gatteschi, Langmuir, 2007, 23, $2389-2397$.

23 T. Sugawara, Yuki Gosei Kagaku Kyokaishi, 2004, 62, 447-458 (in Japanese).

24 J. L. Gallani, J. Le Moigne, L. Oswald, M. Bernard and P. Turek, Langmuir, 2001, 17, 1104.

25 M. M. Matsushita, N. Ozaki, T. Sugawara, F. Nakamura and M. Hara, Chem. Lett., 2002, 31, 596.

26 M. Mannini, D. Rovai, L. Sorace, A. Perl, B. J. Ravoo, D. N. Reinhoudt and A. Caneschi, Inorg. Chim. Acta, 2008, 361, 3525.

27 E. B. Troughton, C. D. Bain, G. M. Whitesides, R. G. Nuzzo, D. L. Allara and M. D. Porter, Langmuir, 1988, 4, 365.

28 S. Chen, L. Li, C. L. Boozer and S. Jiang, Langmuir, 2000, 16, 9287-9293.

29 H. Munakata, S. Kuwabata, Y. Ohko and H. Yoneyama, J. Electroanal. Chem., 2001, 496, $29-36$.

30 J. H. Osiecki and E. F. Ullman, J. Am. Chem. Soc., 1968, 90, 1078-1079.

31 B. Neises and W. Steglich, Angew. Chem. Int. Ed. Engl., 1978, 17, 522-524.

32 Z. Y. Zhang, A. Berg, H. Levanon, R. W. Fessenden, D. Meisel, J. Am. Chem. Soc., 2003, 125, 7959.

33 M. Lucarini, P. Franchi, G. F. Pedulli, P. Pengo, P. Scrimin and L. Pasquato, J. Am. Chem. Soc., 2004, $126,9326$.

34 C. Gentilini, F. Evangelista, P. Rudolf, P. Franchi, M. Lucarini and L. Pasquato, J. Am. Chem. Soc., 2008, 130, 15678.

35 V. Chechik, H. J. Wellsted, A. Korte, B. C. Gilbert, H. Caldararu, P. Ionita and A. Caragheorgheopol, Faraday Discuss., $2004,125,279$.

36 V. Lloveras, E. Badetti, V. Chechik and J. Vidal-Gancedo, J. Phys. Chem. C., 2014, 118, 21622-21629.

37 M. Brust, M. Walter, D. Bethell, D. J. Schiffrin and R. Whyman, J. Chem. Soc., Chem. Commun., 1994, 801-802.

38 J. N. Molin, K. M. Salikhov and K. I. Zamaraev, Spin Exchange; Springer: Berlin, 1980.

39 a) G. R. Luckhurst, Mol. Phys., 1966, 30, 543-550; b) G. R. Luckhurst, In Spin Labeling. Theory and Applicarions; Berliner, L. J., Ed.; Academic: New York, 1976; Vol. 6, p 133.

40 a) V. N. Parmon and G. M. Zhidomirov, Mol. Phys., 1974, 27, 367; b) V. N. Parmon, A. I. Kokorin, G. M. Zhidomirov and K. I. Zamaraev, Mol. Phys., 1975, 30 $695 ;$ c) V. N. Parmon and G. M. Zhidomirov, Mol. Phys., 1976, 32, 613; d) V. N. Parmon, A. I. Kokorin and G. M. Zhidomirov, Zh. Srrucr. Khim., 1977, 18, 132; e) V. N. Pannon, A. I. Kokorin and G. M. Zhidomirov, Stable Diradicals; Nauka Publishers: Moscow, 1980; 240 pp (in Russian).

41 J. Heinzer, Mol. Phys., 1971, 22, 167; Quantum Chemistry Program Exchange 1972, No. 209.

42 a) J. Sedó, D. Ruiz, J. Vidal-Gancedo, C. Rovira, J. Bonvoisin, J. P. Launay and J. Veciana, Adv. Mater., 1996, 8, 748; b) C. Rovira, D. Ruiz-Molina, O. Elsner, J. Vidal-Gancedo, J. Bonvoisin, J-P. Launay and J. Veciana. Chem. Eur. J., 2001, 7, 240; c) N. Gautier, F. Dumur, V. Lloveras, J. Vidal-Gancedo, J. Veciana, C. Rovira and P. Hudhomme, Angew. Chem. Int. Ed., 2003, 42, 2765; d) P. Hudhomme, F. Dumur, N. Gautier, A. Gorgues, V. Lloveras, J. Vidal-Gancedo, J. Veciana and C. Rovira, J. Phys. IV France, 2004, 114, 509; e) V. Lloveras, J. Vidal-Gancedo, D. Ruiz-Molina, T. Duarte, J., -F. Nierergarten, J. Veciana and C. Rovira, Faraday Discuss., 2006, 131, 291-305; f) V. Lloveras, J. Vidal-Gancedo, T. M. Figueira-Duarte, J.-F. Nierengarten, J. J. Novoa, F. Mota, N. Ventosa, C. Rovira and J. Veciana, J. Am. Chem. Soc., 2011, 133, 5818; g) F. Oton, V. Lloveras, M. Mas-Torrent, J. Vidal-Gancedo, J. Veciana and C. Rovira Angew. Chem. Int. Ed., 2011, 50, 10902-10906.

43 a) O. Jürgens, J. Vidal-Gancedo, K. Wurst, K. Sporer, K. Worm, P. Jaitner and J. Veciana, J. Mol. Cryst. Liq. Cryst., 1997, 306, 249-256; b) O. Jürgens, J. VidalGancedo, K. Wurst, K. Sporer, B. Bildstein, H. Schottenberger, P. Jaitner and J. Veciana, Inorg. Chem., 1998, 37, 4547-4558.

44 a) Kanzaki, Y.; Shiomi, D.; Kaneda, C.; Ise, T.; Sato, K.; Takui, T. J. Mater. Chem., 2006, 16, 2064-2073; b) Zhao, M.; Li, Z.; Peng, L.; Tang, Y.-R.; Wang, C.; Zhang, Z.; Peng, S. Bioorg. Med. Chem., 2007, 15, 2815-2826; c) Zhao, M.; Li, Z.; Peng, L.; Tang, Y.-R.; Wang, C.; Zhang, Z.; Peng, S. Europ. J. Med. Chem., 2008, 43, 1048-1058; d) Bi, W.; Cai, J.; Xue, P.; Zhang, Y.; Liu, S.; Gao, X.; Li, M.; Wang, Z.; Baudy-Floc'h, M.; Green, S. A.; Bi, L. Bioorg. Med. Chem. Lett., 2008, 18, 1788-1794.

45 a) S. Link and M.A. El.Sayed, J. Phys. Chem. B, 1999, 103, 4212-4217; b) W. Haiss, N. T. K. Thanh, J. Aveyard and D. G. Fernig, Anal. Chem., 2007, 79, 42154221.

46 M. M. Álvarez, J. T. Khoury, T. G. Schaaff, M. N.Shafigullin, I. Vezmar and R. L. Whetten, J. Phys. Chem. B, 1997, 101, 3706-3712.

47 Brust, M.; Walter, M.; Bethell, D.; Schiffrin, D. J.; Whyman, R., J. Chem. Soc., Chem. Commun., 1994, 801-802.

48 Hostetler, M. J.; Wingate, J. E.; Zhong, C. J.; Harris, J. E.; Vachet, R. W.; Clark, M. R.; Londono, J. D.; Green, S. J.; Stokes, J. J.; Wignall, G. D.; et al., Langmuir, 1998, 14, 17-30.

49 M. Lucarini and L. Pasquato, Nanoscale, 2010, 2, 668-676.

50 J. A. Weil, J. R. Bolton, J. E. Wertz, Electron Paramagnetic Resonance, John Wiley \& Sons, New York, 1994

51 a) D. Maspoch, L. Catala, P. Gerbier, D. Ruiz-Molina, J. Vidal-Gancedo, K. Wurst, C. Rovira and J. Veciana, Chem. Eur. J., 2002, 8, 3635-3645; b) O. Jürgens, J. Vidal-Gancedo, C. Rovira, K. Wurst, C. Sporer, B. Bildstein, H. Schottenberger, P. Jaitner and J. Veciana, Inorg. Chem., 1998, 37, 4547-4558; c) O. Elsner, D. Ruiz-Molina, J. Vidal-Gancedo, C. Rovira and J. Veciana, Chem. Comum., 1999, 7, 579-580; d) O. Jürgens, J. Cirujeda, M. Mas, I. Mata, A. Cabrero, J. VidalGancedo, C. Rovira, E. Molins and J. Veciana, J. Mater. Chem., 1997, 7, 1723-1730.

52 R. W. Murry In Electroanalytical Chemistry; A. J. Bard, Ed.; Marcel Dekker: New York, 1984; Vol 13, pp 191-368 and references therein.

53 J. C. Love, L. A. Estroff, J. K. Kriebel, R. G. Nuzzo and G. M. Whitesides, Chem. Rev., 2005, 105, 1103-1169.

54 D. G. Castner, K. Hinds and D. W. Grainger, Langmuir, 1996, 12, 5083.

55 T. Ishida, M. Hara, I. Kojima, S. Tsuneda, N. Nishida, H. Sasabe and W. Knoll, Langmuir, 1998, 14, 2092-2096. 
56 E. Ito, J. Noh and M. Hara, Chem. Phys. Lett., 2008, 462, 209-212.

57 O. Cavalleri, G. Gonella, S. Terreni, M. Vignolo, P. Pelori, L. Floreano, A. Morgante, M. Canepa and R. Roland, J. Phys.: Condens. Matter, 2004, 16, S2477S2482.

58 R. S. Alger in Electron Paramagnetic Resonance: Techniques and Applications; Interscience Publishers: New York, 1968. 